\title{
Auxiliary Platform Blended Learning Curriculum Research and Application based Cloud Computer-In Computer Application Foundation Case
}

\author{
Jinglan Jiang ${ }^{1, a}$ \\ ${ }^{1}$ Liuzhou Railway Vocational Technical College, Liuzhou, Guangxi, China \\ a717285053@qq.com
}

Keywords: Blended learning, cloud computing, computer applications, auxiliary platform.

\begin{abstract}
With advances in technology, teaching and learning has changed dramatically from a single didactic teaching writing on the blackboard to blackboard teaching, to use a slide projector teaching, teaching and a variety of multimedia teaching courseware. Among them, the recent popularity of blended learning model has played an important role in teaching through multimedia blended learning mode, teaching quality and teaching methods has been greatly improved. This paper focuses on the application of teaching in blended learning model, designed to improve the teaching quality of teaching and make personal recommendations, refined and improved blended learning mode in College Teaching.
\end{abstract}

\section{Introduction}

Blended learning model is popular in recent years, new teaching methods, through blended learning mode, give full play to the leading role of the main role of students and teachers. It is based on the traditional teaching on added multimedia teaching methods to promote teaching, training students' abilities from multiple angles, the ability of students independent study. With the rapid development of advanced technological means of modern technology, multimedia, computer sets and other widely used in school teaching, as a teacher in the new period should have blended learning model in teaching in order to teach students more efficient knowledge and develop students' skills [1].

\section{Blended Learning Overview}

Blended learning is a new trend in the development of modern educational technology, refers to computer-assisted teaching and traditional teaching combined with independent learning and collaborative learning combine in a learning mode. Including learning about different learning environment based on hybrid teaching model different teaching theory, mixing teacher-led activities with the students' participation in classroom teaching and in-line mixing [1], mixing different teaching media, lectures mixed with virtual classrooms or virtual communities, etc.

Blended learning theory is a new theory after learning Constructivist Learning Theory. Its essence lies in the integration of modern teaching and traditional teaching theory, teaching a variety of integrated media mix integrating a variety of teaching content, as well as a variety of learning styles in support of cloud services at build personalized teaching environment, at the right time teachers through appropriate media tools provide a suitable learning content for learners [2], to facilitate interaction between teachers and students, cooperation between life and learning, so that the quality of teaching and learning is optimized.

Many people think that the traditional learning blended learning and online learning combined together, but we are talking about here is not simply blended learning online learning and face to face learning simple mixing but for all learning elements rational selection and combination, so that learning is optimized [2]. The blended learning cloud services platform is supported by teaching about all elements combined with each other, there are blended approach to learning, blended learning resources, learning style mixing, etc., shown in Fig 1. 


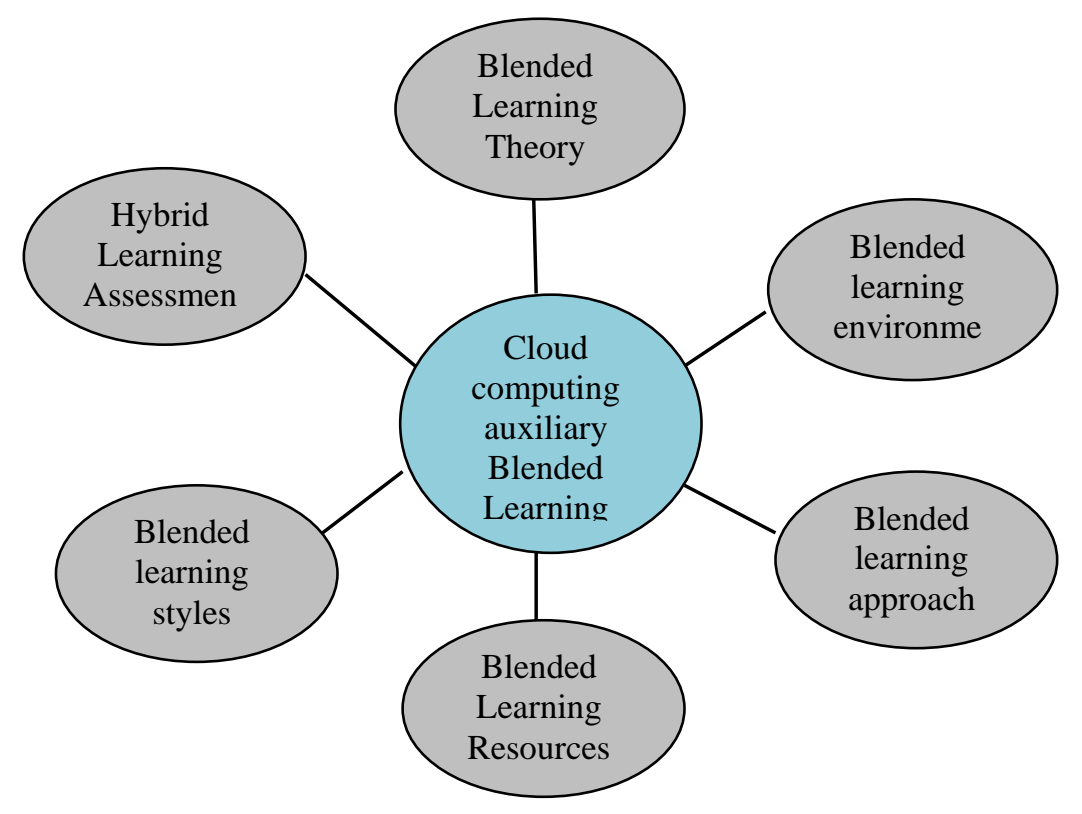

Fig.1 Blended learning platform supported by cloud

\section{Cloud Services Platform to Support Blended Learning Mode Under Construction}

The Overall Design. According to the design process, combined with Baihui platform applications function, design the overall structure of Baihui platform under "Computer Network" assisted teaching platform, as shown in Fig 2.

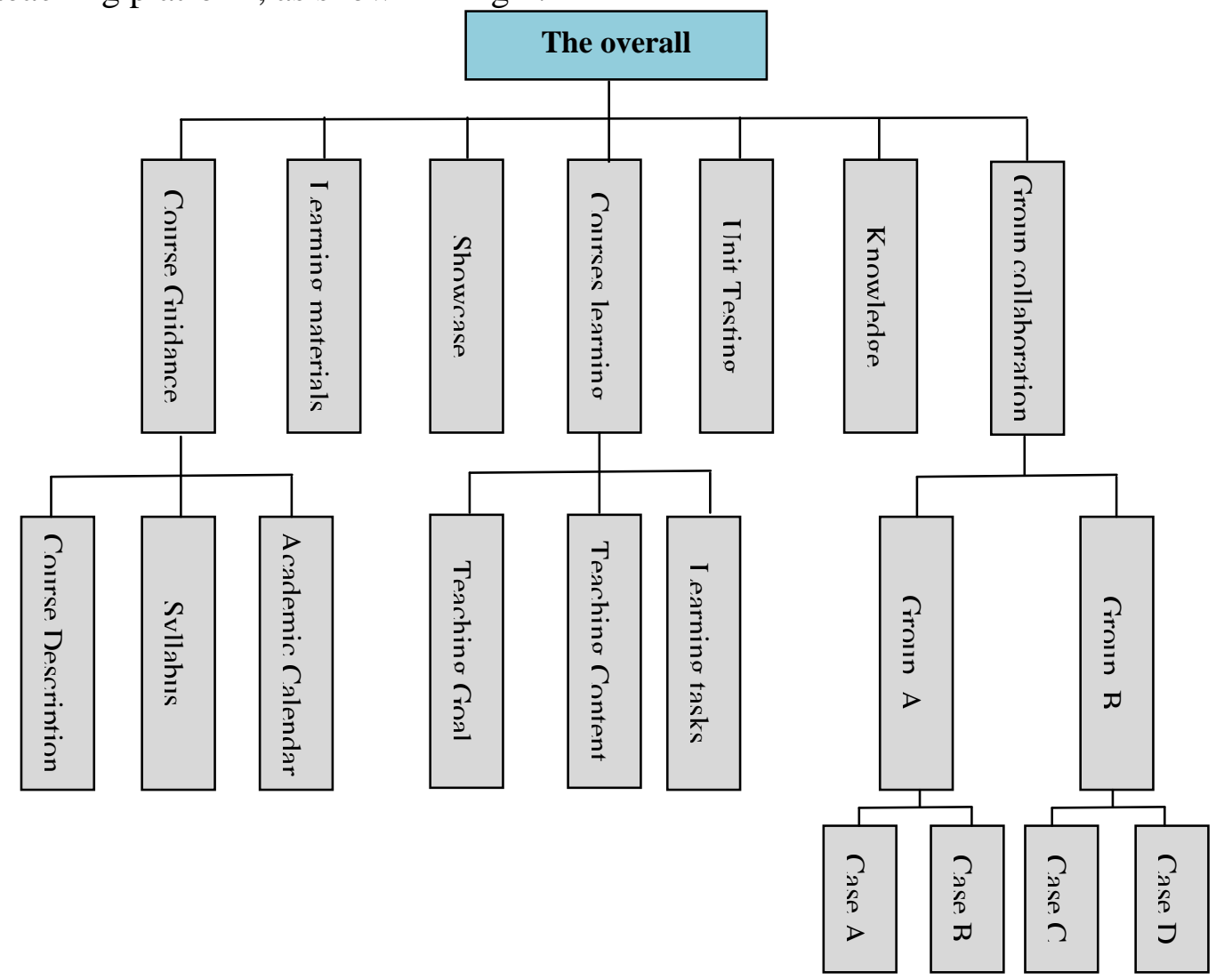

Fig. 2 The overall structure of the secondary teaching platform

Packets can be seen from the figure, based on the overall structure of the cloud-assisted teaching platform program uses a hierarchical structure, in the overall framework in which the horizontal navigation is the introduction of the course when the self-study, when the forum for the exchange of 
knowledge expansion and other parts of the course, each section contains additional content related to, for example, part of a school curriculum guide: course description, syllabus, teaching goals [2].

Model Constitution. According to the overall design of the hybrid design flow and the secondary platform Baihui platform analysis and design of the main components of blended learning model, combining Baihui platform specific model design includes a self-learning mode, collaborative learning model, project-based learning mode.

Self-learning mode. Independent learning is teaching students according to the resources available for self-exploration, self-selected, self-construction, self-innovation and other forms of learning. Students in the learning process of building a personalized, the learning resource requirements are relatively high, whether the resource-rich learning a certain extent, affect students' independent learning [3]. For example: electronic lesson plans and PPT courseware, pictures, videos, etc., as well as some of the courseware counseling information such as: books, papers, references, etc., to expand the depth and breadth of student learning.

Numerous studies have shown: student during learning, if it is based on their own interests, have chosen to learn, the learning efficiency is the highest; if it is forced to learn under other pressures, and easy to learn reverse psychology,it is not conducive to the students to construct meaningful knowledge.

Collaborative learning mode. Whether traditional and modern classroom teaching information technology can support teaching and collaborative learning has become a typical mode of learning. Collaborative learning model is the use of cooperative learning to promote students' understanding of the organizational form of process knowledge and grasp of team members to achieve the appropriate collaborative learning is an integral part of the learning objectives [3]. According to the overall design of the structure, it is in a collaborative study carried out in the course of the model used to cooperation, role playing, to solve some problems, and design.

Project-Based Learning.Project-based learning is a student-centered teaching model, in this teaching model, students selected projects under the guidance of teachers, and planning appropriate project, completion of the final results of the project, then the results of the exchange, and finally the evaluation of the achievements of outstanding common learning [4].

Under the project platform, teachers specify the project theme, students select the project, planning and design to final results of other students and teachers, demonstration projects, on the other hand by Compare achievements, not only enable students to develop the habit of objective and fair assessment, and cultivate students' aesthetic ability, so as to enhance the ability of self-design [4], shown in Fig 3.

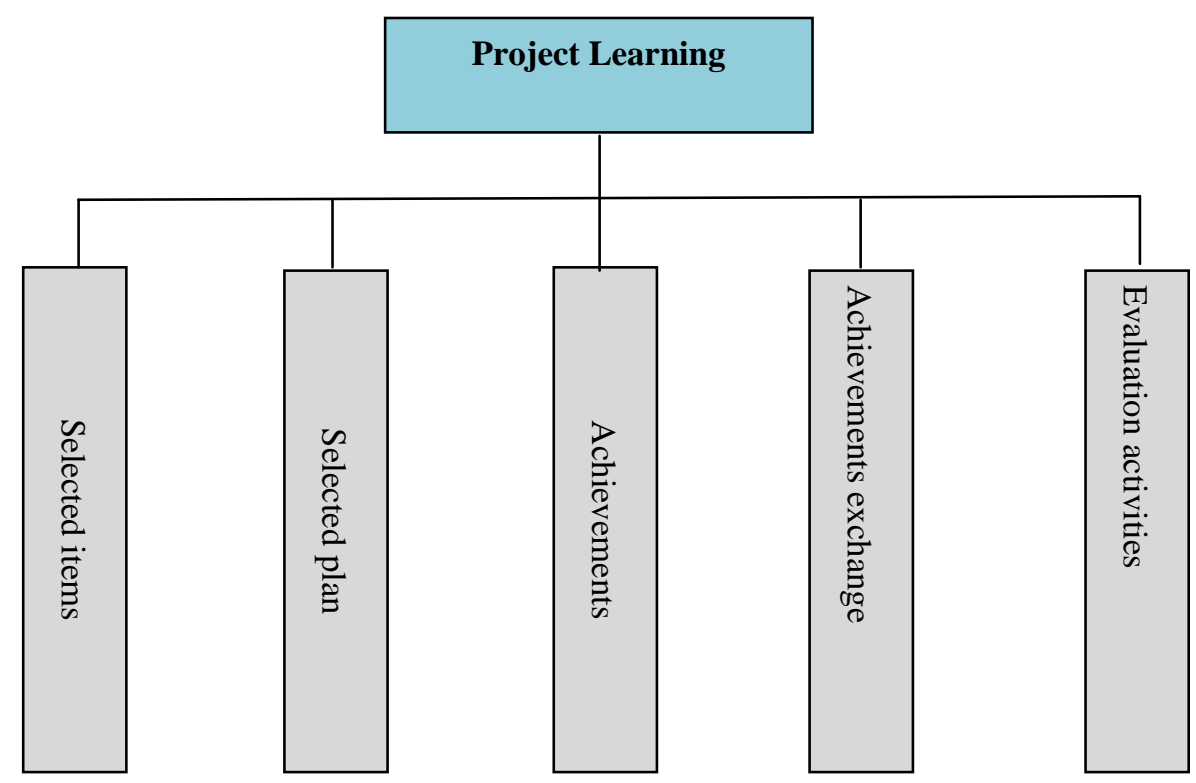

Fig. 3 Project Learning Model 


\section{Application Analysis - Computer Application Basic Course}

Basic computer courses are compulsory courses college students, under the "Computer Basics" course in the use of Word to create a table, for example, Hybrid Learning in this curriculum application [4].

Course Overview.1) Course content: search and use online resources, reading relevant literature and materials, understanding Word software, related concepts and applications making table. Under the guidance of teachers compare several common forms, method of making master table. 2)Learning Environment: Lectures: multimedia classroom; online learning: web-based teaching platform blog and message class's 3) Teaching Evaluation: Process Evaluation: Class tests, online testing, reflection evaluation: online discussions and summative evaluation.

Course Design. In this case, about the Word of knowledge consists of three modules [5]: 1)Compulsory Part: Word theoretical basis. Word of the theoretical part of the design into a single unit, including: Word in history, Word use range, Word's basic operation to highlight the Word software tabulation functions. 2)Elective part: Word deeper level of application, students learn through this section, can be combined with their own interests, their imagination, using more tabulation tool to create form. 3)References Section: This section provides a large Word application cases, such as the use of Word resume production of the curriculum and typeset form beautification.

Teaching Evaluation. Again you can choose the form of teaching evaluation form for students on the course of the evaluation [5].These are just a part of the teaching evaluation form, we choose the class of 50 students in a statistics, statistics show that 70.6 percent of people think that this course is designed reasonable; $86.2 \%$ of people through the course of this program was the interest, rather than the boring basics of books; 76.5 were satisfied with the teacher's teaching methods; also $65 \%$ of the students after school will continue to study this course on the Internet-related content; $82 \%$ of people think that teachers resources from the points. Through feedback, we saw most of the students interested in the course, and will continue to learn in a class, such as the next instruction basis.

\section{Summary}

Cloud computing auxiliary platform based on the rational use of blended learning model can improve teaching efficiency and students' practical ability and brains. Blended learning model is an emerging discipline, is the product of technological development, but also promote further development of science and technology. With more comprehensive knowledge, it is useful to increase greater weight to students for study and work. In the future, teaching, blended learning model will be further widely used research on this direction also has unlimited prospects.

\section{References}

[1] Ch.Y. Liao, Teachers' Role blended learning mode to expect research. Hubei Adult Education Institute, 2012, pp. 11-14. (In Chinese)

[2] B.G. Lin, Computer Basics course "Blended Learning" Mode. CULTURE, 2006, pp.65-68. (In Chinese)

[3] J. Tang. Blended learning mode in college English teachers IT training applications. Modern Educational Technology, 2011, pp.35-38. (In Chinese)

[4] X.Y. Cai , Multimedia Teaching Status and Improvement Measures. Lishui reported, 2009, pp.23-29. (In Chinese)

[5] A.M. Wei, X.F. Zheng. Situation of College Teaching and network improvements. 2009, pp.4-9. (In Chinese) 